\title{
A STRUCTURAL EQUATION MODEL ON MOTIVATION IN LANGUAGE LEARNING
}

\author{
Victor P. Lato, $\mathbf{P h D}^{1}$, Elleine Rose A. Oliva, EdD ${ }^{2}$
}

Article DOI: https://doi.org/10.36713/epra8996

DOI No: 10.36713/epra8996

\begin{abstract}
The purpose of this study, to determine the most suitable model for motivation in language learning. It aims to ensure the significant relationship between the exogenous variable: writing strategy, study habits, classroom climate, and the endogenous variable in language learning motivation. In addition, non-experimental correlational research design and structural equation models to determine the most appropriate motivational model in motivation language learning. However, a stratified random sampling technique to select 436 participants from ninth-grade students from secondary public schools in Region XI. The following statistic used: mean, Pearson r, regression, and structural equation model (SEM). The exogenous variables have a significant correlation with endogenous variables that the fifth model adapted result of the study. In connection with, exogenous variables acquired a high descriptive level. The writing strategy includes planning, implementation, and revision; study habits include: time management, learning environment, forecasting skills and preparation, note-taking, reading skills, writing skills, and language skills; classroom climate includes: teacher support, student independence, interaction, and collaboration in class; and the endogenous variable acquired a high descriptive level of motivation in language learning that included: instrumental and integrative motivation.
\end{abstract}

KEYWORDS: education, writing strategies, study habits, classroom climate, language learning motivation, structural model, Philippines

\section{INTRODUCTION}

It is a significant challenge to enhance the level of students' lack of language learning when the teachers teach that it is essential for them to learn a language because of the quantity of linguistic variation that serves as a hurdle in their learning. However, it appears that a lack of drive is preventing many pupils from honing their language learning skills (Nduwimana 2019). As a result, students can't acquire the language if they have no motivation to do so (Alizedah 2016). As a result, (Ravindran 2016) argued that pupils adopt various motivations, approaches, and instructional styles to understand the language.

However, this study is to know the level of motivation in language learning and thereby assess the importance of motivation towards language learning. Thus, (Hashim, Hashim, and Yunus 2018) mentioned that the importance of motivation towards language learning serves as a way for students to learn the language well. In fact, according to the study by (Bedir and Mavis 2015), it is easier for students to learn the language through various activities, games, singing, and showing pictures. Furthermore, (Dembo and Seli 2016) identified that students were successful as individuals when there was a motivation for the excellence of their language learning. Meanwhile, according to (Sengkey 2018), the students need to know about the proper use of language that they can use in real life. It can be a result of the study that motivation contributes towards language learning.

According to them (Coyle, Nicolás-Conesa, and Roca de Larios 2016), mastery of the following writing processes is particularly relevant for language learning today as a writing technique. In this regard, Suwantharathip (2015) defines the study habit as a collaborative way to create motivation for language acquisition that includes cognitive and metacognitive strategies. Furthermore, according to Arianti (2016), most students who learn a language in the classroom experience fear and shame from their teachers lest they make a grammatical error due to a lack of vocabulary, which has negative consequences for them and leads to a lack of 
confidence in learning the language. Furthermore, encouraging students to learn the language in the classroom would benefit their varied talents, including acquiring excellent writing skills according to the technique they have used and sharpening their interest, which has become a habit in the classroom (Graham and Santangelo 2016)

In other words, it has been demonstrated that studying language learning is crucial so that teachers can react to students' demands for language learning that can be used in comprehension and other learning styles. Thus, when students fully establish the drive to learn the language that acts as a guide towards efficient student interaction rather than using language, the writing method, study habits, and classroom climate may be successfully implemented. In this regard, past research has found studies connected to motivation in language learning that is localized. Still, no study has found a correlation between writing method, study habits, and classroom atmosphere as a structural approach to language learning motivation. The researcher's purpose is to develop the best appropriate model that can be used as a launching pad for students to achieve a high level of language learning skills. The researcher recommended looking into variables that may aid in research in local and global awareness and diverse research in connections to provide a good foundation on the level of motivation in language learning of students.

\section{RESEARCH OBJECTIVES}

This study aimed to determine the most appropriate model of motivation in language learning to writing strategy, study habits, and classroom climate. In this regard, the researcher wants to answer the following specific objective:

1. Know the level of writing strategy when evaluated according to:

1.1. Planning;

1.2. Practice and revision.

2. Determine the level of students' learning habits when evaluated according to:

2.1. Time management;

2.2. Learning environment;

2.3. Skills and preparation in obtaining forecasts;

2.4. note-taking;

2.5. Reading skills;

2.6. Writing skills and

2.7. Language skills.

3. Determine the level of classroom climate if analyzed according to:

3.1. Teacher support;

3.2. Being an independent student and

3.3. Interaction and collaboration with classmates.

4. The level of motivation in language learning is evident when evaluated according to:

4.1. Instrumental motivation and

4.2. Integrative motivation.

5. State the significant relationship between writing strategy, study habits, classroom climate, and motivation for language learning.

6. Identify the significant effect of the writing strategy, study habits, and classroom climate on language learning motivation.

7. Know the model best suited to motivation in language learning.

\section{HYPOTHESIS}

The null hypotheses of this study were developed and tested at a 0.05 level of significance in which:

1. There is no significant relationship between:

1.1 writing strategies;
1.2 study habits and
1.3 classroom climate

2. No variable significantly affects language learning motivation.

3. There is no model best suited to language learning motivation.

\section{METHODOLOGY}

The design of this study is a quantitative research method of data collection that describes the relationship of a number to anything that can measure in a systematic way of investigating different times or 
situations. It is a measure question with a significant correlation to each variable to explain, predict, and control the situation (Leedy 1993). In addition, this study will use causal research design as the design methodology because of the types of variables that can be measured. In turn, causal or causal design comparative research is used in this study to compare two or more causal groups or an independent variable that has already occurred (Creswell 2013). Thus, descriptive correlational research design refers to establishing the existence of a predictive relationship. It uses two or more data sets to evaluate the significant correlation of each variable.

Thus, this study focused on adapting the data to hit models in writing strategy, learning habits, classroom climate, and language learning motivation. Consequently, the causal design was to describe the relationship of the overt and covert variables of the study (Hatami 2018). In addition, the Structural Equation Model (SEM) can help strengthen the integrity of output obtained in response to the process followed by the research to the essential data needed by the study to maintain proficiency in the study's results by emphasizing the following steps: defining the model, collecting data, estimating what to be modeled, modeling analysis, and possibly making changes to the study's actual development in response to the overall result of the student's response to the learning objective.

\section{SAMPLING DESIGN}

The design of this study is a quantitative research method of data collection that describes the relationship of a number to be measured in a systematic way of investigating different times or situations. To this, to assess the level of motivation in language learning with a total of 436 study participants from grade nine of Junior High School in the academic year 2020-2021.

In turn, this study is a structural model with multiple fit indices that influence sample size. However, according to some researchers, the required sample size for the structural model should be at least 200 and 200500 (Çelik and Yilmaz , 2013). However, (Karagoz 31-38) affirmed that the structural model correlates with the theoretical model data. In this regard, the structural model is more suitable for theory testing than other methods. Meanwhile, to fully obtain the appropriate number of participants from different divisions in Region XI that use sloven's formula for the result of participants in each division as enrolled in the 2020 school year- 2021 using the stratified random sampling technique in a total of 436 with a .05 significance label. Stratified random sampling (SRS) in which the population into subgroups called "Strata". From within each stratum, consistent random sampling to select a sample of each stratum (Lang, Liberty and Shmakov, 2016).

Thus, the researcher considers the 436 study participants who answered the questionnaire according to the scientific process that the researcher will use in selecting the participants. Stratified random sampling technique to determine the number of students in each public secondary school of Junior High School in Region $\mathrm{XI}$ according to the methodology used that each individual has an equal opportunity to select as a participant (Baridalyne 195-197). Further, the stratified random sampling technique is a process that will ensure that the selected data is used randomly from the number table or generated list corresponding to the random number.

Therefore, study participants will be from the ninth grade of Junior High School in Region XI public schools currently enrolled in the 2020-2021 school year in the Department of Education and included in the stratified random collection technique.

\section{STATISTICAL DESIGN}

To fully evaluate the significant data collected is necessary to use the following statistics:

Mean. To determine the level of writing strategy; know the level of learning habits; determine the classroom climate to develop motivation for language learning.

Standard Deviation. It is to measure the frequency distribution.

Pearson Product Moment Correlation. It determines the importance of the relationship between writing strategy, study habits, classroom climate, and motivation in language learning.

Multiple Regression. It cultivates significant predictors of motivation in language learning.

Structural Equation Model. What this study used was consistent with the Structural Approach to produce the most appropriate model. Thus, in the analysis, it is necessary to analyze a factor in the hidden variable showing suggesting a boundary value of 0.05 while Ullman (2006) the 0.45 in modeling the safety of the development culture that is to ensure the removal characteristic. Therefore, according to them Bentler and Savalei (2010), the essence of the test is to determine the nature of the removal of significant correlations with the characteristics and other factors hidden in the latter of the Structural Structural Model. The boundary value affects the sample size a range of 0.45 to 0.50 is appropriate if considered. In addition, this tool is to determine the best model appropriately to the organizational essence. 
The goodness of Fit Statistics for Alternative Model through Analysis of Moment Structure (AMOS). Thus, it determines the most appropriate model that all presented has important clues that should be consistent with the following premise as follows:

- Chi-Square/Degree of Freedom (CMIN/DF) $0<$ value $<2$

- P Value > .05

- Normative Fit Index (NFI)> .95

- Comparative Fit Index (CFI)>.95

- The goodness of Fit Index (GFI)> .95

- Tucker-Lewis Index> .95

- Root Mean Square Error of Approximation (RMSEA) <.05

- P-close> .50

\section{GEOGRAPHICAL AREA}

This study aimed to cultivate the level of motivation in language learning of students in the ninth grade of Junior High of Region XI. In this regard, to assess the level of language learning motivation with 436 study participants from grade nine of Junior High School in the academic year 2020-2021. In turn, this study is a structural equation model with multiple fit indices that influence sample size. However, according to some researchers, the required sample size for the structural model should be at least 200 and 200-500 (Çelik and Yilmaz 2013). But, (Karagoz 2016) affirmed that the structural model correlates with the theoretical model data; the structural model is more suitable for theory testing than other methods.

Meanwhile, to fully obtain the appropriate number of participants from different divisions in Region XI, using Slovens formula to measure the number of participants in each division as enrolled in the 2020 school year- 2021 using the stratified random sampling technique in a total of 436 with a .05 significance. In addition, stratified random sampling (SRS) in which the population into subgroups called Strata within each stratum, consistent random sampling was used to select a sample of each stratum (Lang, Liberty, and Shmakov 2016). Thus, the researcher considers the 436 participants who answered the questionnaire according to the scientific process that the researcher will use in selecting the participants. Therefore, study participants will be from the ninth grade of Junior High School in the public school of Region XI for the 2020-2021 school year in the Department of Education and the stratified random collection technique. Thus, the selected participants have the right to answer the questionnaire provided the required study data. Furthermore, study participants will be from the ninth grade of Junior High School in the public school of Region XI. The latter is currently in the 2020-2021 school year in the Department of Education and the stratified random sampling technique.

\section{RESULTS}

This chapter presents writing strategy, learning habits, and classroom climate: a standard structural approach to language learning. In this chapter, the survey result showed writing strategy, learning habits, and classroom climate: a structural equation model approach to language learning. The data collected as a result of the survey conducted using questionnaire has thoroughly analyzed the variables derived from the indicators such: strategy writing that will evaluate the level of indicators such as planning, execution, and revision; will also the study habits that include time management, learning environment, skills and preparation to assessment taking, note-taking, reading skills, and language skills; the level of indicators from the variable classroom climate will also evaluate the level of teacher support, student independence, and interaction as well as the motivation in language learning as an independent variable which will analyze the level of the following indicators that instrumental and interactive motivation.

\section{Level of Writing Strategy}

Table 1 shows the first variable according to the result of the study data related to the level of writing strategy consisting of three indicators: and with a total of thirty (30) statements that participants achieved a descriptive high level that proved, the writing strategy was frequently seen, concerning which the planning, implementation and revision indicators also obtained a total standard deviation (SD) of 0.53 and a total mean score of 3.84 . 
Table 1

Level of Writing Strategy

\begin{tabular}{|l|l|l|l|}
\hline Indicator & SD & Mean & Descriptive Level \\
\hline Planning & 0.61 & 3.90 & High \\
\hline Execution & 0.58 & 3.71 & High \\
\hline revision & 0.64 & 3.91 & High \\
\hline Total & 0.53 & 3.84 & High \\
\hline
\end{tabular}

It can be seen from the data that the first indicator in the writing planning strategy achieved a high descriptive level showing that frequently seen and obtained a standard deviation of 0.61 with a mean score of 3.90. But, the second indicator garnered a high descriptive level that showed detected and a standard deviation of 0.58 and had a mean score of 3.71. Meanwhile, the third revision indicator achieved a descriptive high level showing high frequency and obtained a standard deviation of 0.64 with a mean score of 3.91 .

\section{Level of Study Habits}

Table 2 second variable according to the result of data from the study behavior-related level in the study consisting of seven indicators: and forty-eight (48) statements achieved of the overall high descriptive level confirming that study habits often observed. They obtained a total standard deviation of 0.52 and a total mean score of 3.75. According to the data result, the first time management indicator achieved a high descriptive level, which showed that time management is frequent and obtained a standard deviation of 0.62 with a mean score of 3.74. However, the second indicator learning environment achieved a high descriptive level showing a standard deviation (SD) of 0.63 and a mean score of 3.82. Thus, the third indicator practice and preparation in obtaining the forecast obtained a descriptive level of high showing that frequently detected and a standard deviation (SD) of 0.61 and had a mean score of 3.72 .

Table 2

Level of Study Habits

\begin{tabular}{|c|c|c|c|}
\hline Indicator & SD & Mean & Descriptive Level \\
\hline Time Management & 0.62 & 3.74 & High \\
\hline Learning Environment & 0.63 & 3.82 & High \\
\hline Forecasting Skills and Preparation & 0.61 & 3.72 & High \\
\hline Note Takings & 0.70 & 3.73 & High \\
\hline Reading Skills & 0.68 & 3.69 & High \\
\hline Writing Skills & 0.69 & 3.85 & High \\
\hline Language Skills & 0.71 & 3.69 & $\mathrm{High}$ \\
\hline Total & 0.52 & 3.75 & High \\
\hline
\end{tabular}

However, the fourth note-taking indicator achieved a high descriptive level showing that it was frequently detected and obtained a standard deviation (SD) of 0.70 and had a mean score of 3.73. The fifth reading proficiency indicator achieved a high descriptive level showing a standard deviation (SD) of 0.68 and had a mean score of 3.69. However, the sixth writing proficiency indicator got a descriptive high level showed that were frequently detected and obtained a standard deviation (SD) of 0.69 and had a mean score of 3.85. But, the seventh language proficiency indicator achieved a high descriptive level showing that it was frequently seen and obtained a standard deviation (SD) of 0.71 and had a mean score of 3.69. 


\section{Level of Classroom Climate}

Table 3 the classroom climate level consisting of three indicators with a total of twelve statements. Thus, the result of the study concerning the level of classroom climate has acquired a descriptive high level showing that obtained total standard deviation (SD) of 0.61 and with a mean score of 3.93. the first indicator of teacher support achieved a high descriptive level showing that it was frequently seen and had a standard deviation (SD) of 0.71 and a mean score of 4.08. But, the second indicator of student independence achieved a descriptive level of high showing that was frequently seen and obtained a standard deviation (SD) of 0.80 and had a mean score of 3.85. However, the third class interaction and collaboration indicator achieved a high descriptive level showing that it was frequently observed and obtained a standard deviation (SD) of 0.80 and had a mean score of 3.87 .

\section{Table 3}

Level of Classroom Climate

\begin{tabular}{|l|l|l|l|}
\hline Indicator & SD & Mean & Descriptive Level \\
\hline Teacher Support & 0.71 & 4.08 & High \\
\hline Being an Independent Student & 0.80 & 3.85 & High \\
\hline Classmate Interaction and Collaboration & 0.80 & 3.87 & High \\
\hline Total & $\mathbf{0 . 6 1}$ & $\mathbf{3 . 9 3}$ & High \\
\hline
\end{tabular}

\section{Level of Motivation in Language Learning}

The level of motivation in language learning with two indicators consisting of twenty statements (20) achieved descriptive high level, showing frequently and obtained a total standard deviation (SD) of 0.61 and a mean score of 3.90. Thus, the first instrumental motivation indicator achieved a high descriptive level showing that it was frequently detected and obtained a standard deviation (SD) of 0.61 and had a mean score of 3.82. However, the second integrative motivation indicator achieved a high descriptive level showing that it was medals detected and obtained a standard deviation (SD) of 0.72 and had a mean score of 3.98 .

\section{Table 4}

Level of Motivation in Language Learning

\begin{tabular}{|l|l|l|l|}
\hline Indicator & SD & Mean & Descriptive Level \\
\hline Instrumental Motivation & 0.61 & 3.82 & High \\
\hline Integrative Motivation & 0.72 & 3.98 & High \\
\hline Total & $\mathbf{0 . 6 1}$ & $\mathbf{3 . 9 0}$ & High \\
\hline
\end{tabular}

Table 5 showed the significant influence of writing strategy, study habits, and classroom climate on language learning motivation. The result revealed the significance level of the writing strategy, study learning habits, and classroom climate on language learning motivation that obtained a total F-value of 214.374 , R-value of .773, $\mathrm{R}^{2}$ value .598 , and a p-value of .000 was less than 0.05 at the significance level. The overall result agreed with the rejection of the null hypothesis that supported the alternative. 


\section{Table 5}

Significant Influence of Writing Strategies, Learning Habits and Classroom Climate on Language Learning Motivation

\begin{tabular}{|c|c|c|c|c|c|}
\hline \multicolumn{6}{|c|}{ Language Learning Motivation } \\
\hline \multicolumn{2}{|c|}{ Exogenous Variables } & $B$ & $\beta$ & $t$ & Sig. \\
\hline Constant & & .167 & & 1.127 & .261 \\
\hline Writing Strategy & & .382 & .335 & 7.334 & .000 \\
\hline Study Habits & & .316 & .269 & 5.380 & .000 \\
\hline Classroom Climate & & .276 & .276 & 6.705 & .000 \\
\hline $\mathrm{R}$ & .773 & & & & \\
\hline $\mathrm{R}^{2}$ & .598 & & & & \\
\hline$\Delta \mathrm{R}$ & .595 & & & & \\
\hline F & 214.374 & & & & \\
\hline$\rho$ & .000 & & & & \\
\hline
\end{tabular}

We can emphasize from the data that the writing strategy has standardized and unstandardized coefficients of .382 and .335 , and has a t-value of 7.334 and p-value of .000 (Significant); study practice had standardized and unstandardized coefficients of .316 and .269 , had a t-value of 5.380 and had a p-value of .000 (Significant); and the classroom climate had standardized and unstandardized coefficients of .276 and .276 and had at-value of 6.705 , with a p-value of .000 (Significant).

The direct effect of the non-independent variable serves as a correlation as the predictor that the variables and the non-independent variable can intervene to traverse one or more variables. Table 6 shows the effect of the latent variable between the indicators to generate regression in writing strategy, learning habits, and classroom climate that significantly affected endogenous variable motivation in language learning $(\mathrm{p}<.05)$.

Table 6

Direct and Indirect Effects of the Independent Variables on Motivation in language Learning of Best Fit Model

\begin{tabular}{|l|l|l|l|}
\hline Variables & Direct Effect & Indirect Effect & Total Effect \\
\hline Writing Strategy & .338 & - & .338 \\
\hline Study Habits & -.041 & .248 & .207 \\
\hline Classroom Climate & .601 & .212 & .813 \\
\hline
\end{tabular}

\section{Most Appropriate Model of Motivation in Language Learning}

The final research question aims to determine the model most appropriate to the variables as a predictor of motivation in language learning. Table 1 that needs to be modified to respond to the needs of the goodness of fit measures. The five models generated in this study are summarized as seen in

Table 7.

In determining the most appropriate model, it is only necessary to comply with all indexes contained within the acceptable range. The Chi-square/degrees of freedom value must be between 0 and 2, with a corresponding pvalue greater than or equal to 0.05 . 
The Root Mean square of Error Approximately value must be less than 0.05 and have a corresponding p-close value greater than or equal to 0.05 . Other indexes such as the Normed Fit Index, Tucker-Lewis Index, Comparative Fit Index, and Goodness of Fit Index must be higher than 0.90. According to the data, the generated structural model 1 shows the direct impact of exogenous variables: writing strategy, learning habits, and classroom climate and direct causal relationship with endogenous variables motivation on language learning. In turn, this model is inappropriate because $\mathrm{p}$-value $=.000 ;$ RMSEA $=.141$ and has a $\mathrm{p}$-value $=.000$ that all

\title{
Table 7
}

Summary of Goodness of Fit Measures of the Five Generated Models

\begin{tabular}{|c|c|c|c|c|c|c|c|c|}
\hline Model & $\begin{array}{l}\text { P-value } \\
(>0.05)\end{array}$ & $\begin{array}{l}\text { CMIN } \\
\text { DF } \\
(0<\text { value }< \\
2)\end{array}$ & $\begin{array}{l}\text { GFI } \\
(>0.95 \\
)\end{array}$ & $\begin{array}{l}\text { CFI } \\
(>0.95)\end{array}$ & $\begin{array}{l}\text { NFI } \\
(>0.95)\end{array}$ & $\begin{array}{l}\text { TLI } \\
(>0.95)\end{array}$ & $\begin{array}{l}\text { RMSE } \\
\text { A } \\
(<0.05)\end{array}$ & $\begin{array}{l}\text { P-close } \\
(>0.05)\end{array}$ \\
\hline 1 & .000 & 9.665 & .809 & .792 & .775 & .749 & .141 & .000 \\
\hline 2 & .000 & 6.827 & .878 & .863 & .844 & .831 & .116 & .000 \\
\hline 3 & .000 & 2.959 & .927 & .954 & .933 & .943 & .067 & .000 \\
\hline 4 & .000 & 3.452 & .912 & .942 & .920 & .929 & .075 & .000 \\
\hline 5 & .062 & 1.456 & .983 & .945 & .983 & .991 & .032 & .910 \\
\hline
\end{tabular}

\section{Legend: \\ CMIN/DF - Chi-Square/Degrees of Freedom \\ GFI $\quad-$ Goodness of Fit Index \\ RMSEA $\quad-$ Root Mean Square of Error Approximation}

\author{
NFI -Normed Fit Index \\ TLI - Tucker-Lewis Index \\ CFI - Comparative Fit Index
}

index values do not meet the requirement of each premise.

The finally generated structural model 5 showing the direct causal relationship of exogenous variables: writing strategy, learning habits, and classroom climate toward endogenous variable motivation in language learning is the most developed. Thus, the most appropriate model is measured in acceptability, as shown in Table 7. Chi-Square divided by degrees of freedom with 1.456 with a P-value of .062 proved the most suitable model. Thus, it is also fully supported by the Root Means Square of Error Approximation index of .032, which is below the significance level with a P-close of .910. The other indexes such as the Normed Fit Index, TuckerLewis Index, and Comparative Fit. Thus, all dimensions are by the standards. It is shown here in Table 8 the direct effect of writing strategy and classroom climate on language learning motivation, but study habits have indirect effects on language learning motivation. Thus, arrows from the predictor variable are described, according to the illustration shown from the left side to the right side, where the non-independent variable passes directly through the other variables. Therefore, the combination of the three exogenous variables had a significant influence on motivation in language learning. An R2 of .598 indicated a 59.8\% difference in motivation in language learning if we could relate it to writing strategy, study habits, and classroom climate. In turn, this means that $40.2 \%$ of the variation of motivation in language learning to other variables not covered in this study. In further analysis, the table showed that of the three exogenous variables: the writing strategy had the contribution with $($ Beta $=.382$, and with P-value $=.000)$, followed by learning habits with $($ Beta $)=.316$, and with P-value $=.000)$ and the lowest was the classroom climate with (Beta =-. 276, and with P-value $=.000)$. Consequently, three exogenous variables writing strategy, study habits, and classroom climate, had significantly influenced language learning motivation.

\section{SUGGESTION}

The researcher proposed the following recommendation based on the result of the study with a high level of the writing strategy, study habits, classroom climate, and motivation in language learning. In addition, the researcher recommends that there is a chance to increase the level of this study to a very high level. Furthermore, the three exogenous variables (writing strategy, study habits, and classroom climate) suggest that students focus 
on the three exogenous variables. When the level of these variables increases, language learning motivation also increases. But, in the literature, it is seen that when there is high support by parents and teachers about enhancing the writing strategy, there is a big chance that language learning motivation is also high. Parents' support for their children's study habits, on the other hand, will make a substantial contribution to the rate at which pupils acquire the language, which will be taken into account by school administrators and teachers when adjusting the classroom climate. There's also the fact that the pupils' language learning abilities are excellent because there are no barriers to their learning.

The following are recommendations for writing strategy, study habits, classroom climate, and language learning motivation in this section: To begin, review the standard K-12 Curriculum at each student level to determine what skills they should master in writing, study habits, and the classroom climate for language learning through adequate instructor encouragement. Therefore, to ensure no obstacle to learning, the classroom environment is suitable for their learning. In addition, for adapting to learning: first, to review the standard K-12 Curriculum at each student level and what skills they should motivate to the students, so they learn language; second, have a review of the Department of Education, teaching skills related to language learning; third, review the syllabus of grade nine teachers to see if the language-learning approach is appropriate; fourth, conduct seminars and workshops for teachers teaching grade nine in Region XI related to language learning; fifth, invite a speaker with fluency in Motivational Language Learning; sixth, seminar and workshop conducted through Google Meet, Zoom and other modality. In other words, the next researcher may consider other predictor variables in language learning motivation required to perform the study in the public secondary school of Region XI.

\section{CONCLUSION}

Based on the study result on writing strategy, study habits, and classroom climate show a significant influence on the language learning motivation that the overall results agree with the rejection of the null hypothesis that supported the alternative. In summary, this study developed a structural model showing the direct causal relationship of exogenous variables: writing strategies, study habits, and classroom climate toward endogenous language learning motivation variables is the most appropriate model developed. This research is based on the theory of language learning strategy, also known as Language Learning Strategy, which created a theoretical framework in language learning based on a cognitive process that influences social awareness and effectively contributes to the character of each individual. It also includes understanding in language learning, which processes information to be fully understood. In turn, language learning processes and language structure are increasingly rising towards having a high level of learning (Griffiths and Oxford 2014). In addition, as a proposition according to the study by (Read 2010), he suggested the Inquiry, Modeling, Shared, Collaborative, Independent (IMSCI) model as support which to be an effective strategy used within the classroom to students to hone their writing skills as a language learning strategy.

\section{REFERENCES}

1. Alizedah, M. (2016). The Impact of Motivation of English Language Learning. Islamic Azad University: Iran. Use the "Insert Citation" button to add citations to this document 50-56.

2. Ariyanti, A. (2016). Psychological factors affecting EFL students' speaking performance. ASIAN TEFL: Journal of Language Teaching and Applied Linguistics, 1(1), 77-88.

3. Bedir, G. \& Maviş, F. (2015). "2nd year students' and their teacher's perspectives on English language program applied for the first time in 2012-2013 academic year." International Journal on New Trends in Education and Their Implications, 4, 205-215

4. Bentler, Peter \& Savalei, Victoria (2010). "Analysis of correlation structures: Current status and open problems." In S. Kolenikov, D. Steinley, \& L. Thombs (Eds.), Statistics in the Social Sciences(2010):(pp. 1-36).

5. Baridalyne, N. (2012). "Sampling, sample size estimation and randomisation. Indian J Med Spec 2012;3:195197.

6. Celik, H., \& Yilmaz, V. (2013). Structural Equation with Lisrel 9.1 Modeling. Ankara: Ani Publishing. 61-73.

7. Coyle, Y., Nicolás-Conesa, F. \& Roca de Larios, J. (2016). Focus on writers: Processes and strategies.In R. M. Manchón \& P. K. Matsuda (Eds.), The handbook of second and foreign language writing.Berlin: DeGruyter Mouton. 267-286.

8. Creswell, J. (2013). Research design: Qualitative, quantitative, and mixed methods approaches, 4th Edition (4th edition). Thousand Oaks: SAGE Publications, Inc. 12.

9. Dembo, M., \& Seli, H. (2016). Motivation and learning strategies for college success: a focus on self-regulated learning. New York: Routledge.76-89.

10. Griffiths, C. \& Oxford, R. (2014). "The twenty-first century landscape of language learning strategies." System, 43,(2014):1-10. Retrieved from doi:10.1016/j.system.2013.12.00957. 
11. Graham, S., \& Santangelo, T. (2016). A comprehensive meta-analysis of handwriting instruction. Educational Psychology Review, 28,225-265.

12. Hashim, H., Hashim, H., \& Yunus, M. (2018). Language Learning Strategies used by Adult Learners of Teaching English as a Second Language (TESL). TESOL International, 13,4, 39-48.

13. Hatami, R. (2018).Development of a protocol for environmental impact studies using causal modeling. Water Res. 138, 206-223.

14. Lang, K., Liberty, E., \& Shmakov, K. (2016). Stratified Sampling Meets Machine Learning. In Proc. ICML 23202329.

15. Leedy, P. (1993). Practical research: planning and design. New Jersey: Prentice-Hall.1-18.

16. Nduwimana, I. (2019). Pure sciences students' attitudes towards learning English: The case of University of Burundi. International Journal of Research in English Education, 4(2),

$1-13$. https://doi.org/10.29252/ijree.4.2.1.

17. Ravindran, S. (2016). Modes of learning English as a second language and the role of motivation: A case study on the second year students of the Faculty of Arts, University of Jaffna. ELT Voices- International Journal for Teachers of English, 6(6), 5-15.

18. Read, S. (2010), "A model for scaffolding writing instruction: IMSCI." Reading Teacher, 64(1),(2010). 47-52. doi:10.1598/RT.64.1.5. Print

19. Sengkey, V. (2018). Student Attitudes and Motivation in Learning English. Human Behavior, Development and Society, 17, 115-122.

20. Suwantharathip, O. (2015). Implementing reading strategies based on collaborative learning approach in an English class." Reading Matrix: $\quad$ An International Online Journal, 15(1),91-101.

21. Ullman, J. (2006). "Structural equation modeling." In B. G. Tabachnick \& L. S. Fidell (Eds.), Using multivariate statistics, (5th ed.;(2006) pp. 653-771). Boston: Allyn \& Bacon. 